\title{
How Does Collaborative 3D Screen-Based Computer Simulation Training Influence Diagnostic Skills of Radiographic Images and Peer Communication?
}

\author{
Tor Sodestrom, Lars Hall, Tore Nilsson, \& Jan Ahlqvist \\ Umea University, Sweden
}

\begin{abstract}
This study compares the influence of two learning conditions - a screen-based virtual reality radiology simulator and a conventional PowerPoint slide presentation - that teach radiographic interpretation to dental students working in small collaborative groups. The study focused on how the students communicated and how proficient they became at radiographic interpretation. The sample consisted of 36 participants -20 women and 16 men - and used a pretest/posttest group design with the participants randomly assigned to either a simulation-training group (SIM) or conventional-training group (CON) with three students in each collaborative group. The proficiency tests administered before and after training assessed interpretations of spatial relations in radiographs using parallax. The training sessions were video-recorded. The results showed that SIM groups exhibited significant development between pretest and posttest results, whereas the CON groups did not. The collaboration in the CON groups involved inclusive peer discussions, thorough interpretations of the images, and extensive use of subject-specific terminology. The SIM group discussions were much more fragmented and included more action proposals based on their actions with the simulator. The different learning conditions produced different results with respect to acquiring understanding of radiographic principles.
\end{abstract}

Keywords: Educational computer based simulations; Collaborative learning; Health care education; 3D Simulations; Peer communication

\section{Introduction}

Teachers and educational researchers often discuss how learning conditions influence specific learning tasks. This article focuses on one of these learning conditions: educational computer assisted simulations (ECAS). The research on ECAS is and has been extensive comprising various disciplines such as science education and health care education. One area that has gained interest is how ECAS can support the development of professional expertise in health care (Issenberg, Mcgaghie, Petrusa, Gordon, \& Scalese, 2005). In dental education there are different skills that students must learn to develop professional expertise. One such skill is the ability to interpret radiographic images. Conventional radiographs are two-dimensional representations of three-dimensional objects where no information about depth of relationships between objects is available. Spatial relations can, however, be deduced by analyzing radiographs exposed from different directions and therefore an important part of dental education includes training students to interpret 3D information in radiographic images. However, learning radiographic principles is difficult and complex (cf. Engel, 2008) and a 3D computer simulation was developed that allow students to practice interpretation skills and 
receive timely feedback, by providing images of internal anatomical structures of a patient model while simultaneously providing real time rendered radiographs (Nilsson, 2007).

In most cases, research findings have suggested that ECAS is more effective than other conventional teaching methods such as traditional textbook lessons. For example, lessons that teach blood circulation (Holzinger, Kickmeier-Rust, Wassertheurer, \& Hessinger, 2009), physics principles, and the use of scientific instruments (Finkelstein et al., 2005; Rieber, Tzeng, \& Tribble, 2004; Yeh, 2004;) using ECAS work better than lessons that only use traditional textbook lessons, textual feedback, and graphical feedback. A basic interpretation, highlighted in the research, of why ECAS provides better learning outcomes is that it improves the way in which students construct and apply knowledge. ECAS is considered to contribute to opportunities for students to ruminate, evaluate, reformulate, compare, and integrate the material to be learned (e.g., Dalgarno \& Lee, 2010; de Freitas \& Oliver, 2006; Lane, Slavin, \& Siv, 2001; Rieber et al., 2004).

Although the research is solid it has mainly emphasized individual ECAS training (e.g., Chang, Chen, Lin, \& Sung, 2008; Engum, Jeffries, \& Fisher, 2003; Holzinger et al., 2009; Quinn, Keogh, McDonald, \& Hussey, 2003). Krange, Moen and Ludvigsen (2012, p. 831) also emphasize that simulation environments in general (e.g., manikins, patient simulators or virtual environments) in health care education have mainly focused on individual's training of technical skills and performance of procedures (see also Nivala, Säljö, Rystedt, Kronkvist, \& Lehtinen, 2012).

However, in line with a learning discourse influenced by more socio-constructivist approaches to learning the collaborative approach has been acknowledged as beneficial for learning purposes in ECAS training (Bolton, Saalman, Christie, Ingerman, \& Linder, 2008; Ingerman, Linder \& Marshall, 2009; Rogers, 2011). From a general view, the socio-constructivist perspective emphasizes that knowledge is constructed through a meaning making process (Jonassen, Howland, Moore, \& Marra, 2003) and arises from the mediation of meanings (cf. Sfard, 1998; Wenger, 1998). On basis of this theoretical argument, collaboration and support from peer students is assumed to contribute to the sharing of arguments and opinions within a group, encouraging the kind of reflection that leads to a deeper learning of the subject (e.g., Mayer, Dale, Fraccastoro, \& Moss 2011). Individuals frame the same situation in different ways and are thereby able to contribute unique learning and knowledge building in a collaborative setting (e.g., Jonassen et al., 2003; Mörch, Dolonen, \& Naevdal, 2005).

When we turn to the research that concerns screen-based simulations the research with a collaborative design has focused on various aspects. In only a few studies interaction and communication patterns exhibited by students during screen-based computer simulation training has been paid attention to (cf. Krange et al., 2012). In such studies prior knowledge is found to have an impact on collaboration and learning interactions (e.g., Hmelo-Silver, 2003; Liu, Andre, \& Greenbowe, 2008) but also that query construction influences the training process (Hmelo \& Day, 1999).

In this study, we investigated interaction and communication patterns in screen-based ECAS training by comparing interpretation and interaction skills of students who worked in triads with a screen-based 3D-virtual reality radiology simulator with those working in triads with an image pair task (2D-PowerPoint slides) of radiographic images to train radiographic interpretation. The general framework guiding the study draws on a socio constructivist view that learning takes place when learners actively 'construct' new understandings for themselves through the mediation of, or their engagement with other group members, a computer 
simulation, conventional training, or a combination of these. Based on this, the study investigated whether small group work improves the students' interpretation skills and what type of verbal communication emerges under the computer simulated condition and the conventional condition.

\section{Methodology}

The research design was built around an experimental core. Participants were drawn from undergraduate students at the dentistry program at Umeå University enrolled in an oral and maxillofacial radiology course. Thirty-six students - 20 women and 16 men - in their fourth semester voluntarily participated in this randomized experimental study. The study comprised three parts. First, a proficiency test was administered before the training started. Based on these results, the students were randomized into two groups - a simulation group (SIM group) or an image pair task group (CON group). Second, students were trained to identify the third dimension in radiographs using parallax. The SIM group worked one hour with a 3D-radiology simulator to perform four structured exercises. The CON group studied for one hour using pairs of $x$-ray images shown in a PowerPoint presentation. The training was performed in small collaboration groups with three students in each group. All the groups were adjusted to include at least one male or one female participant since the practical teaching in small groups normally consists of both men and women. The training was video-recorded. Third, a proficiency test and a questionnaire were administered after training. An outline of the design is presented in Table 1 below.

Table 1. Design of the Study

\begin{tabular}{llll}
\hline & Input & Process & Output \\
\hline Variables & Pre-training & Training Simulation group & Student experience \\
& proficiency & Training Conventional group & Post-training proficiency \\
$\begin{array}{l}\text { Evaluation of } \\
\text { variable }\end{array}$ & Proficiency test & Observation; video-recording & $\begin{array}{l}\text { Questionnaire } \\
\text { Proficiency test }\end{array}$ \\
\hline
\end{tabular}

In this article the focus is on the proficiency development and communication patterns and therefore the questionnaires are not presented. The design and procedures of the study were approved by the university ethical committee.

\section{The Proficiency Tests}

The proficiency test (pretest and posttest) was developed by two dental scientists teaching at the dentistry program. The test comprised three separate subtests that addressed the interpretation of spatial relationships in radiographs using parallax (Nilsson, 2007). The principle subtest assessed the participants' understanding of the principles of motion parallax. The projection subtest assessed the participants' ability to apply the principles of motion parallax. The radiography subtest assessed the participants' ability to locate object details in authentic radiographic images using motion parallax. Each part was graded from 0 to 8 giving a total of 24 points. In this study, the proficiency analyses are based on the total score from all three tests. These tests have previously been used to compare students training individually 
with the simulation and students training with a conventional alternative. For a description of the test design and validity and reliability issues, see Nilsson (2007).

\section{The Radiology Simulator}

The simulator is a standard PC equipped with simulation software. It has two monitors, one presenting a three-dimensional anatomical model, $\mathrm{x}$-ray tube, and film, the other presenting two-dimensional $x$-ray images (Figure 1). The control peripherals used for interaction include a standard keyboard, a 3D and a conventional mouse, as well as a special pen-like controlling device (tracker). Using the simulator, the students performed real-time radiographic examinations of a patient's jaw. The simulator uses a virtual reality (VR) technique to allow the user to position models of the patient, $x$-ray machine, and sensor in any desired position.

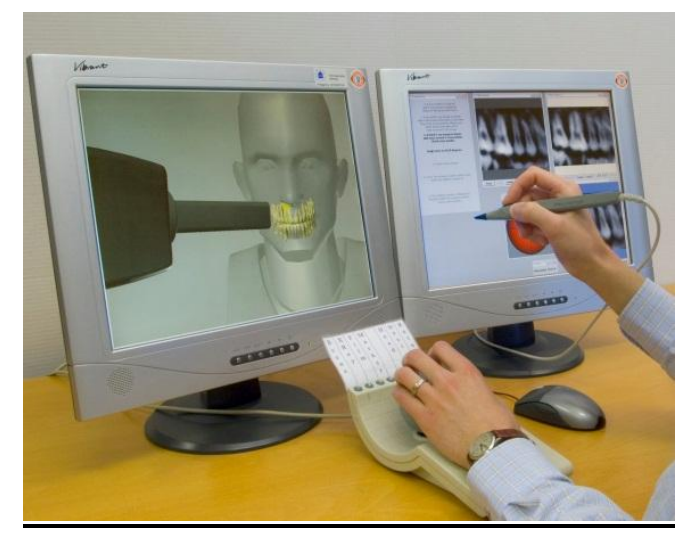

Figure 1. Dental Student Working with the Radiology Simulator (During the study, workgroups of three students collaborated to perform the tasks).

\section{Training Sessions}

For both groups, the training sessions focused on object localization procedure. They were onehour long, the groups worked collaboratively with their tasks, and a teacher acted as technical support. The setup can be described as free collaboration with students themselves deciding how to manage the task.

\section{Simulation Training}

Exercises have been developed to allow the student to study the principles of motion parallax and to perform object localization using the technique. It is possible to view how the twodimensional $x$-ray image changes in real-time when the model is examined in different projections (a technique called fluoroscopy) and experiment in an improvised manner (Nilsson, 2007).

The SIM group was able to choose continuously from four types of structured exercises aimed at developing understanding of and ability to apply the principles of motion parallax and to locate object details in radiographic images. The teacher started the session with a 
demonstration of the separate exercises designed for training object localization in the simulator and then the groups continued by themselves. In essence, the students were presented with a task that required interpretation of radiographic images and operation of the simulator. When students positioned the simulation objects in what they deemed to be the correct way and requested feedback from the simulator (by pressing a button labeled 'Next'), they were given visual and numerical information about their own model-position and the correct model-position. Based on this, the simulation tasks were designed to give an opportunity to re-position the model before submitting their final solution. In addition, this final solution was given numerical feedback on distance between actual position and a correct position. For a more detailed description about the simulator tasks see Nilsson (2007).

\section{Conventional Training}

The CON group worked with x-ray image pair cases presented with MS PowerPoint slides. Each case consisted of two or three intra-oral radiographs that were presented on a monitor accompanied with questions concerning changes in projection and objects position in depth. When they continued to the next slide, correct answers and commentaries were provided. The students discussed radiographic projection theory to develop an understanding of and ability to apply the principles of motion parallax and to locate object details in the images. The computer used in the control group was a standard PC equipped with keyboard, mouse, and one monitor.

\section{The Video Observations}

Video recordings were used to capture the training sessions (cf. Hindmarsh, 2010; Rystedt \& Lindwall, 2004). Twelve groups were recorded and twelve one-hour recordings were produced. The recordings captured the upper half part of the students while neither the computer screen nor the teacher was visible. The analysis of the video recordings focused more on verbal communication which has been a recurring focus in the research in exploring the mediation of or the engagement with the learning environment as it can reveal participants' use of mental tools and collaborative focus (Enyede, 2003; Mercer, 2005). The analysis was performed in two phases to capture the verbal communication. In phase one, three questions were posed to a number of randomly chosen videotapes:

- What are the students talking about?

- How are they talking about it?

- How do they relate to each other and to the learning environment as a whole?

These questions produced thematic answers. Phase one identified and generated categories. The categories were inductively created based on student conversations and reasoning during the performance of the tasks. In relation to what the students talked about, the category interpretation included suggestions on how visual information should be interpreted, the arguments supporting the interpretations, and implications of the interpretations. Action proposals include elaborated suggestions on what should be done and how it should be done while action commenting included less elaborated suggestions as well as comments on something that has been done. Functionality/technology includes talk about the applied technology, while the category theory included general expositions on scientific theories. The 
social comments included non-task-related talk about social relations, jokes, and play. The final category, meta-reflections on learning, included reflections on the learning process or learning outcome more or less related to the exercise. The themes that emerged in relation to how the participants talked were continuity, which refers to previous contributions and/or clearly extends them and appear to be longer threads of reasoning. The other main category, fragmentation, did not make evident references to previous contributions and did not clearly extend them. In addition to these themes, some utterances were placed in an uncertain category. The analytic question about how they discussed the tasks generated two main categories, academic and non-academic. Academic terminology included contributions where the students used subject-specific academic terms, whereas non-academic contributions included talk that was context-dependent terms and utterances. Some of the contributions made by the students were categorized as uncertain.

Phase one ended when no more categories were found, i.e., when saturation had been reached. In phase two, all video data were split into one-minute time segments and coded with the themes generated in phase one. The time segments are our empirical unit of observation. This allowed us to conduct a structured analysis based on an understanding that was influenced by the current set of data. The coding and categorization was performed by one of the researchers. To measure coding stability (Krippendorf, 2004), one of the sessions was recoded by the same researcher and compared with the original for each category. The agreement between original coding and re-coding was $97 \%$ for content, $92 \%$ for terminology, and $98 \%$ for pattern, verbal space, and verbal activity.

\section{Results}

In this section, we present the findings from the comparisons of the different learning conditions with respect to proficiency development and communication patterns during training.

\section{Proficiency Development}

Paired samples $t$-tests in combination with eta-square $\left(\eta^{2}=t^{2} /\left(t^{2}+d f\right)\right)$ were used to measure the proficiency development in the two groups and enable comparison.

Table 2. Paired Sample Statistics SIM and CON Group Proficiency Tests

\begin{tabular}{|c|c|c|c|c|}
\hline & & $M$ & $n$ & $S D$ \\
\hline SIM & Pretest & 12.94 & 18 & 4.291 \\
\hline group & Posttest & 14.94 & 18 & 2.960 \\
\hline CON & Pretest & 13.11 & 18 & 4.351 \\
\hline group & Posttest & 13.00 & 18 & 5.064 \\
\hline
\end{tabular}

Table 2 shows that for the SIM group, we identified a development in test results from pretest to posttest. For the CON group, we identified no development from pretest to posttest. The paired sample test of proficiency development showed a significant development from pretest to posttest for the SIM group (Table 3). 
Table 3. Paired Sample Test of Proficiency in SIM and CON Group

\begin{tabular}{|c|c|c|c|c|c|c|c|}
\hline & & \multirow[b]{2}{*}{$M$} & \multirow[b]{2}{*}{$S D$} & \multirow[b]{2}{*}{$t(17)$} & \multirow[b]{2}{*}{$p$} & \multicolumn{2}{|c|}{$95 \% \mathrm{Cl}$} \\
\hline & & & & & & $L L$ & $U L$ \\
\hline SIM group & Pretest -Posttest & -2.000 & 2.808 & -3.022 & .008 & -3.396 & -.604 \\
\hline CON group & Pretest-Posttest & .111 & 5.279 & .089 & .930 & -2.514 & 2.736 \\
\hline
\end{tabular}

Table 3 illustrates a significant development for the SIM group ( $p=.008)$. An eta-square score of $\eta^{2}=0.34$ means that $34 \%$ of this development is due to the actual training. For CON, we could not identify a significant development from pretest to posttest $(p=.93)$, and an eta-square score of $\left.\eta^{2}=0.04\right)$.

\section{Communication Patterns}

The analysis of the communication patterns during the training sessions shows that there is a difference between the SIM and CON group. Excerpt 1-4 below, illustrates how the students communicated in SIM and CON group and how the communication was encoded based on the observational coding scheme. All excerpts extend over one minute. The first excerpt illustrates a sequence in which two members of the group trying to, step-by-step, interpret what is happening on the screen.

Excerpt 1. Interpretive Content, Subject-Specific Terminology, Continuous Pattern (SIM group)

\begin{tabular}{|r|l|l|}
\hline 1 & Tom & $\begin{array}{l}\text { There. And it is distal from us. And that went away from us. So it should be lingual or } \\
\text { palatial. }\end{array}$ \\
\hline 2 & Sofi & Noo. \\
\hline 3 & Tom & Yeah it went away. \\
\hline 4 & Sofi & It did? I thought it went towards the trajectory. \\
\hline 5 & Tom & This one is distal. So it has moved that way. Or...no. \\
\hline 6 & Sofi & $\begin{array}{l}\text { But like. If you moved it distally, then the ball has moved mesially. Then it is buckal } \\
\text { right }\end{array}$ \\
\hline 7 & Tom & <Click to end step> \\
\hline
\end{tabular}

Another example of the communication within SIM group shows how the computer simulation influences an action-oriented communication with a non-subject specific terminology.

Excerpt 2. Action-Oriented Content, Subject Non-Specific Terminology, Fragmented Pattern (SIM group)

\begin{tabular}{|r|c|l|}
\hline 1 & Liz & And then a bit more upwards, or downwards, sorry. \\
\hline 2 & Mat & Wait...And the head gets tilted when I turn away. \\
\hline 3 & Liz & $\begin{array}{l}\text { But imagine that you hold it by the head. (Laughing.) Imagine that you have him in } \\
\text { front of you. }\end{array}$ \\
\hline
\end{tabular}




\begin{tabular}{|r|l|l|}
\hline 4 & Mat & Or how do you want it? \\
\hline 5 & Liz & Oh, there click. There -ish. Yeah about there, yeah. \\
\hline 6 & Mat & Now it feels very... \\
\hline 7 & Liz & There. That is correct. I would say. \\
\hline
\end{tabular}

The communication in the CON groups exhibits a different character since the group members are not able to follow the consequences of their actions. Excerpt 3 shows a sequence when two students are preoccupied with interpreting radiographs in front of them on the screen.

Excerpt 3. Interpretive Content, Subject-Specific Terminology, Continuous Pattern (CON group)

\begin{tabular}{|r|l|l|}
\hline 1 & Ben & When we took this more distal eccentric, this moved along. So this should be lingual. \\
\hline 2 & Ada & It is lingual of eight's root yes. \\
\hline 3 & Ben & Roots yes, it should be. \\
\hline 4 & Ada & And where is the mandibular canal in relation to eights root? \\
\hline 5 & Ben & Yes. \\
\hline 6 & Ada & You see the mandibular canal only in image c. \\
\hline
\end{tabular}

Although students in the CON group did not have the opportunity to, for example, twist and turn the radiographs, there are also examples of a more action-oriented communication (Excerpt 4).

Excerpt 4. Action-Oriented Content, Subject Non-Specific Terminology, Continuous Pattern (CON group)

\begin{tabular}{|l|l|l|}
\hline 1 & Sam & Should we check it? \\
\hline 2 & Zoe, Bree & Mmm. \\
\hline 3 & Bree & You are the checker. \\
\hline 4 & Sam & Yeah, hehe. \\
\hline 5 & Zoe & How happy I would be if it's right. \\
\hline 6 & Sam & Yeah, hehe. \\
\hline 7 & Zoe & And if I understand why it is right. \\
\hline 8 & All & Haha. \\
\hline 9 & Sam & Yeah, lets continue. \\
\hline 10 & Bree & Yea, so we have time for another. \\
\hline 11 & Sam & Oh, it's the end. \\
\hline 12 & Bree & That was right on time. \\
\hline
\end{tabular}

As we see from the excerpt 1-4, there is a marked difference between the SIM and CON with respect to what they are talking about and how they talk about it during training.

An analysis of all the 12 groups one hour video recordings divided in 60 one-minute time segments and coded with the coding scheme shows regarding what the participants talk about (Figure 2 ) the verbal content in the CON group falls almost exclusively (92\%) under one analytic category: interpretation. The students seem to discuss and negotiate about possible interpretations trying to reach coherent analyses of the images by means of verbal reasoning. 
The verbal activity in the simulation group is distributed over two main analytic categories: interpretation (38\%) and action proposals/commenting (45\%). Based on their actions trying to reach a solution, the students seem to focus on what happens on the screen.

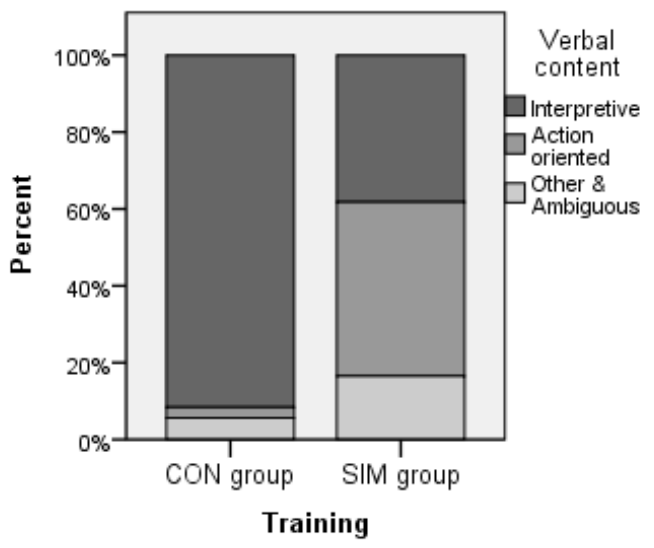

Figure 2. Comparison of Training Forms by Distribution of Verbal Content Over Interpretation, Action Proposals/Commenting, and Other (The other category includes social comments, comments on the technology, meta-reflections on learning, and ambiguous activity and accounts for $50 \%$ of the category in both training forms)

The verbal activity regarding how the participants talk shows that the SIM and CON group differ from each other (Figure 3 ). In the CON group, the verbal activity is distinguished by a continuous pattern in the contributions (92\% of all cases), which is not as clear in the simulation group ( $43 \%$ of all cases). This means that verbal contributions in the control group more often made references to and clearly extended previous verbal contributions.

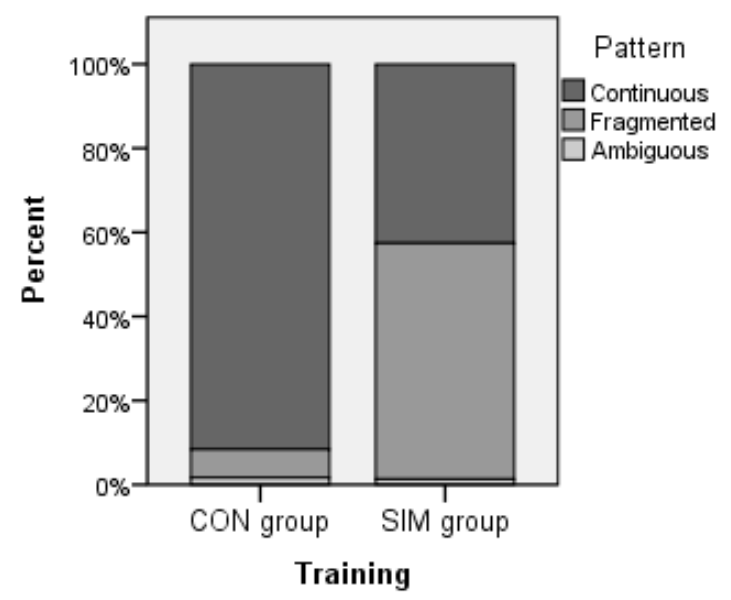

Figure 3. Comparison of Training Forms by Distribution of Expressed Reasoning Over Continuous and Fragmented

The observations of the training process also reveal that the CON groups, more often than the SIM groups, use academic terminology (subject specific) in their argumentation in the discussions ( $86 \%$ for all cases) (Figure 4). The SIM groups apply a more context-dependent, non-academic terminology (subject non-specific) (32\% academic utterances). 


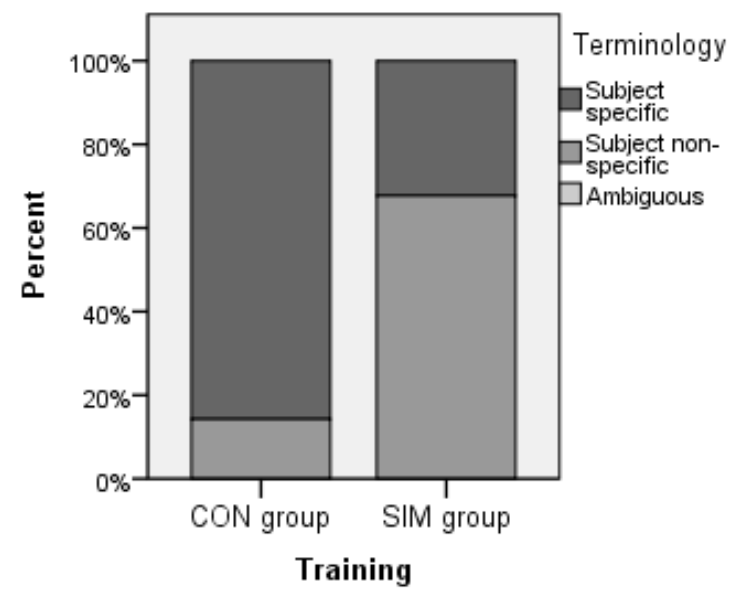

Figure 4. Comparison of Training Forms by Distribution of Terminology Over Academic (Subject Specific) and Non-Academic (Subject Non-Specific)

If we link the categories together and compare the training forms, we see that the relationship between verbal activity and communication patterns differ between the groups. For the CON groups, interpretive content most often is combined with a continuous pattern (89\% of the cases) and academic terminology (subject specific) (83\% of the cases). For the SIM groups, where the action proposals/commenting is the most prominent content in the communication, it is expressed in a more fragmented way ( $84 \%$ of the cases) and with a non-academic terminology (subject non-specific) ( $89 \%$ of the cases).

The main expressed verbal activity in the SIM group is action proposals/commenting, which is distinguished by a fragmented pattern as well as a context-dependent terminology. The main verbal activity in the CON group is interpretation, which is distinguished by a continuous pattern as well as a more academic terminology (Table 4).

Table 4. Summary of the Main Characteristics of the Two Training Forms

\begin{tabular}{lll}
\hline & CON group & SIM group \\
\hline Verbal content & Interpretive & Action oriented \\
Pattern & Continuous & Fragmented \\
Terminology & Academic & Non-academic \\
\hline
\end{tabular}

\section{Discussion}

This study focuses two learning conditions - educational computer assisted simulation and conventional PowerPoint-based training - to learn how to interpret radiological images. The results show that the SIM groups were more proficient at interpreting radiographs. For the SIM group, we identified a significant development from pretest to posttest and we identified no development from pretest posttest in the CON group. We can conclude that while our simulation intervention can contribute significantly to proficiency development, its conventional counterpart cannot. In this case, the improvement of proficiency in the SIM groups' collaborative work supports previous findings focusing individual computer simulation training (e.g., Holzinger et al., 2009; Stoik, 2001). 
Regarding the communication that emerges in the two investigated learning conditions the result from the observations show that the SIM groups exhibit fewer discussions about how to interpret things on the screen and more discussions on performed actions (i.e. what should be done, and how to do it). The SIM groups are also more focused on how to manoeuver the simulator and apply a more context-dependent terminology. Their verbal communication is more fragmented with fewer references to prior contributions from peer students. One possible explanation for the differences in proficiency development that arise between SIM and CON group is that the 3D-computer simulation training can be regarded as an activity that enables the students to, not practically hands-on but virtually, experience a specific concept (cf. the laboratory training model described by Badeleh \& Sheela, 2011). The aim for the SIM group to position an object requires manipulation and observation that captures students' attention and guides them toward relevant areas. This process in the simulation training also ensures that the group is on the right track. Nivala et al. (2012) also noted in their study that visual cues from a computer simulation are important in scaffolding medical students learning of pathology. The students could manipulate 3D-representations and receive immediate feedback, which also influenced the use of action proposals, non-academic terms and more context-dependent language.

On the other hand, the aim for the CON group to express verbally relations between objects in a static image pair contributes to the use of collective interpretations expressed in academic terms with no room for manipulation of the feedback. For the SIM group it is both about the relation between action and feedback on their actions but also that the 3D representation in the simulation training offered better support for the learning of depth relationships and spatial relations. The conventional training form leaves no possibility to explore the subject to learn. Sadler (1989) points out that to improve performance students must be able to monitor the quality of their own work during actual production. This has also been noted by other researchers. Higgins et al. (2011) concludes that multi-touch tables enable a physical structure that makes the discussion history visible for the group members. The results from the SIM groups' communication can then be understood in such a manner that the simulation training, in Sadler words, enables for explicit provision for students themselves to acquire evaluative expertise (Sadler, 1989, p. 143). In this case, the possibility of simulation techniques to offer immediate feedback is important (cf. de Freitas and Neumman (2009) view of game-based training). Finkelstein et al. (2005) claim that "a variety of visual cues in a computer simulation make concepts visible that are otherwise invisible to students" (p. 6). Finkelstein suggests that computer simulations provide perceptual access to concepts of flow, which in this study were hidden from the CON students. Their verbal contributions did not, to the same extent, enable the students to monitor the quality of their own training process.

\section{Concluding Remarks}

To conclude, the two learning conditions mediate learning differently (see Loke et al., 2011) for similar findings on a comparison between simulation training and conventional paper-based training) and consequently how the acquisition of principles is supported. The different learning conditions produced different results with respect to acquiring understanding of radiographic principles. The results indicate that the simulation training provides an experience which opens up for better opportunities to learn clinical knowledge, as in this case, the skill to interpret radiographic images (cf. Engel, 2008). A previous study on individual radiology simulation training also found that the students improved their proficiency compared to students training conventionally (Nilsson, 2007). The SIM training task can be regarded as it 
offers a constructivist environment allowing for experimentation (cf. findings from Chang et al., 2008, de Freitas and Neuman, 2009; Holzinger et al., 2009; Rieber et al., 2004). However, in a practical teaching situation in which individual training requires more resources the results from this study show that collaborative learning may be efficient although not all group members were equally involved in operating the simulator as in individual training. From an educational design perspective the analysis made here cannot be generalized. How computer simulations influence learning is a complex issue depending on a variety of factors. For example, Silvennoinen, Helfenstein, Ruoranen and Saariluoma (2012) show in their study of surgical residents training with a computer simulation that the simulation did not provide sufficient information to users to help them to carry out the task to improve performance. It is possible that another type of feedback from the simulator may have produced a different result in this study. Therefore ECAS has to be dressed in constructivist clothes to enable active exploration with possibilities to monitor progression (cf. Juul Christensen, Heffernan, \& Barach, 2001).

Finally, future research should develop the theoretical underpinnings of research on ECAS in health care education. This is something that is often lacking at least from medical research on the topic. Studies, for example, that focus on the field of computer supported collaborative learning (Dillenbourg, Järvela, \& Fischer, 2009), could be of interest for those trying to combine simulations with collaborative learning. From such a perspective, it would be interesting to further analyze the interactive patterns that emerge in simulation and conventional training. Under which conditions do specific patterns occur and how are they related to proficiency development? This study is limited in some aspects. The students only trained for one hour and we do not know, for example, what repetitive training had contributed to. Had the differences between training forms evened out? Nor do we know how simulator training relates to clinical practice, beyond the analysis of radiographs. Moreover, the discussion made here is based on tentative interpretations of the data which have to be scrutinized further and supplemented with more studies to enable a deeper understanding of learning skills with screen-based computer simulation training. Therefore it would be relevant to compare different conditions for ECAS training. Such analysis can be performed with a larger scale quantitative approach as well as with a smaller scale qualitative approach.

\section{Acknowledgements}

This article is indebted to the Learning Radiology in Simulated Environments Research Project, which is a joint project between Umeå University and Stanford University, funded by Wallenberg Global Learning Network.

\section{References}

Badeleh, A. \& Sheela, G. (2011). The effects of information and communication technology based approach and laboratory training model of teaching on achievement and retention I chemistry. Contemporary Educational Technology, 2(3), 213-237.

Bolton, K., Saalman, E., Christie, M., Ingerman, Å., \& Linder, C. (2008). SimChemistry as an active learning tool in chemical education. Chemistry Education Research Practice, 9(3), 274-284. 
Chang, K-E., Chen, Y-L., Lin, H-Y., \& Sung, Y-T. (2008). Effects of learning support in simulationbased physics learning. Computers and Education, 51(4), 1486-1498.

Dalgarno, B. \& Lee, M.J.W. (2010). What are the learning affordances of 3-D virtual environments. British Journal of Educational technology, 41(1), 10-32.

de Freitas, S. \& Oliver, M. (2006). How can exploratory learning with games and simulations within the curriculum be most effectively evaluated. Computers \& Education, 46(3), 249264.

de Freitas, S. \& Neumann, T. (2009). The use of 'exploratory learning' for supporting immersive learning in virtual environments. Computers \& Education, 52(2), 343-352.

Dillenbourg, P., Järvelä ,S., \& Fischer, F. (2009). The evolution of research on computersupported collaborative learning. In N. Balacheff, S. Ludvigsen, T. de Jong, A. Lazonder \& S. Barnes (Eds.), Technology Enhanced Learning (pp. 3-19). Berlin: Springer.

Engel, P.J.H. (2008). Tacit knowledge and visual expertise in medical diagnostic reasoning: Implications for medical education. Medical Teacher, 30, 184-188.

Engum, S. A., Jeffries, P., \& Fisher, L. (2003). Intravenous catheter training system: Computerbased education versus traditional learning methods. The American Journal of Surgery, 186, 67-74.

Enyedy, N. (2003). Knowledge construction and collective practice: At the Intersection of learning, talk, and social configurations in a computer-mediated mathematics classroom. Journal of the Learning Sciences, 12(3), 361-407.

Finkelstein , N.D., Adams, W.K., Keller, C.J., Kohl, P.B., LeMaster, R., Perkins, K.K.,Podolefsky, N.S. \& Reid, S. (2005). When learning about the real world is better done virtually: A study of substituting computer simulations for laboratory equipment. Physical Review Special Topics - Physics Education Research, 1(1).

Higgins, S., Mercier, E., Burd, L., \& Joyce-Gibbons, A. (2011). Multi-touch tables and collaborative learning. British Journal of Educational Technology. DOI: 10.1111/j.14678535.2011.01259.x

Hindmarsh J. (2010). Peripherality, Participation and Communities of Practice: Examining the patient in dental training. In N. Llewellyn \& J. Hindmarsh (Eds.), Organisation, interaction and practice (pp. 218-240). Cambridge, UK: Cambridge University Press.

Hmelo, C., \& Day, R. (1999). Contextualized questioning to scaffold learning from simulations. Computers \& Education, 32(2), 151-164.

Hmelo-Silver, C. E. (2003). Analyzing collaborative knowledge construction: multiple methods for integrated understanding. Computers \& Education, 41(4), 397-420.

Holzinger, A., Kickmeier-Rust, M.D., Wassertheurer, S., \& Hessinger, M. (2009). Learning performance with interactive simulations in medical education: Lessons learned from results of learning complex physiological models with the HAEMOdynamics SIMulator. Computers \& Education, 52(2), 292-301.

Ingerman, Å., Linder, C. \& Marshall, D. (2009). The learners' experience of variation: Following students'threads of learning physics in computer simulation settings. Instructional Science, 37(3), 273-292. 
Issenberg, B.S., McGaghie, W.C., Petrusa, E.M., Gordon, D.L., \& Scalese R.J. (2005). Features and uses of high - fidelity medical simulations that lead to effective learning: a BEME systematic review. Medical Teacher, 27 (1), 10-28.

Jonassen, D. H., Howland, J., Moore, J., \& Marra, R. (2003). Learning to solve problems with technology: A constructivist perspective (2nd edition). Upper Saddle River, NJ: Merrill Prentice Hall.

Juul, Christensen, U., Heffernan, D., \& Barach, P. (2001). Microsimulators in medical education: An overview. Simulation \& Gaming,3(2), 250-262.

Krange, I., Moen, A., \& Ludvigsen, S. (2012). Computer-based 3D simulation: A study of communication practices in trauma team performing patient examination and diagnostic work. Instructional Science, 40(5), 829-847.

Krippendorff, K. (2004). Content analysis. An introduction to its methodology. Thousand Oaks, $\mathrm{NJ}$ : Sage.

Lane, L.J., Slavin, S., \& Ziv, A. (2001). Simulation in medical education: A review. Simulation\& Gaming, 32(3), 297-314.

Liu, H. C., Andre, T., \& Greenbowe, T. (2008). The impact of learner's prior knowledge on their use of chemistry computer simulations: A case study. Journal of Science Education and Technology, 17(5), 466-482.

Loke, S-W., Tordoff, J., Winikoff, M., McDonald, J., Vlugter, P., \& Duffull, S. (2011). SimPharm: How pharmacy students made meaning of a clinical case differently in paper- and simulation-based workshops. British Journal of Educational Technology, 42(5), 865-874.

Mayer, B.W., Dale, K.M., Fraccastoro, K.A., \& Moss, G. (2011) Improving transfer of learning: Relationship to Methods of Using Business Simulation. Simulation \& Gaming, 42(1), 6484.

Mercer, N. (2005). Sociocultural discourse analysis: Analysing classroom talk as a social mode of thinking. Journal of Applied Linguistics, 1(2), 137-168.

Mörch, A. I., Dolonen, J. A., \& Naevdal, J.E. (2005). An evolutionary approach to prototyping pedagogical agents: from simulation to integrated system. Journal of Network and Computer Applications, 29(2-3), 177-199.

Nivala, M., Säljö, R., Rystedt, H., Kronqvist, P., \& Lehtinen, E. (2012). Using virtual microscopy to scaffold learning of pathology: A naturalistic experiment on the role of visual and conceptual cues. Instructional Science, 40(5), 799-811.

Quinn, F., Keogh P., McDonald, A., \& Hussey, D. (2003). A study comparing the effectiveness of conventional training and virtual reality simulation in the skills acquisition of junior dental students. European Journal of Dental Education, 7(4), 164-169.

Rieber, L.P., Tzeng, S-C. \& Tribble, K. (2004). Discovery learning, representation, and explanation within a computer-based simulation: Finding the right mix. Learning and Instruction, 14(3), 307-323.

Rogers, L. (2011). Developing simulations in multi-user virtual environments to enhance healthcare education. British Journal of Educational Technology, 42(4), 608-615 
Rystedt, H. \& Lindwall, O. (2004). The interactive construction of learning foci in simulationbased learning environments: A case study of an anaesthesia course. PsychNology Journal, 2(2), 165-188.

Sadler, D. R. (1989). Formative assessment and the design of instructional systems. Instructional Science, 18(2), 119-144.

Sfard, A. (1998). On two metaphors for learning and the dangers of choosing just one. Educational Researcher 27(2), 4-13.

Silvennoinen, M., Helfenstein, S., Ruoranen, M., \& Saariluoma, P. (2012). Learning basic surgical skills through simulator training. Instructional Science, 40(5), 769-783.

Stoik, J.H. (2001). Technology's role in collaboration. Community College Journal of Research and Practice, 25(1), 37-46.

Wenger, E. (1998). Communities of practice. Learning, meaning and identity. Cambridge, UK: Cambridge University Press.

Yeh, Y.C. (2004). Nurturing reflective teaching during critical-thinking instruction in a computer simulation program. Computers \& Education, 42(2), 181-194.

Zagal, J.P., Rick, J., \& His, I. (2006). Collaborative games: Lessons learned from board games. Simulation \& Gaming, 37(1), 24-40.

Correspondence: Tor Sodestrom, Department of Education, Umea University, S-901 87 Umea, Sweden 